\title{
A model of a stochastically driven ice sheet with planetary wave feedback
}

\author{
By J. OERLEMANS, Royal Netherlands Meteorological Institute, Postbus 201, De Bilt, \\ The Netherlands
}

(Manuscript received September 20, 1978; in final form June 11, 1979)

\begin{abstract}
The growth and decay of continental ice sheets forms a key problem in dynamical climatology. Apart from knowledge about their behaviour for given external conditions, like the distribution of incoming solar energy, it is desirable to know something about their variability due to forcing with a stochastic character.

This paper presents a simple model of ice-sheet variability in which the interaction between ice sheet and atmosphere is taken into account in a crude way. The model is formulated by a linear second-order differential equation describing the evolution of the ice-sheet size, and is stochastically forced by white noise representing year-to-year weather fluctuations. The results, statistics of ice-sheet size variability, are very sensitive to the model parameters prescribing the ice sheet-atmosphere interaction. For realistic values of those parameters, the standard deviation of the ice-sheet size (in north-south direction) is in the 10-500 km range for a large ice sheet, thus leaving much uncertainty. The main conclusion of the analysis is that stochastic forcing of ice sheets is important only if strong positive feedback between ice sheets and atmosphere exists.
\end{abstract}

\section{Introduction}

In global climatology, continental ice sheets play a very important role. Their growth and decay are thought to be major controlling factors (and results, of course) of the global climate regime and its variability. Consequently, in any study of climate variability on longer time scales, whether this is an observational one or a modelling effort, ice sheets should be taken into account. During the last decade, this has been fully realized. The CLIMAP-project (CLIMAP, 1976) and the large number of experiments with energy balance climate models (EBM's) in which highly simplified ice sheets are incorporated (Budyko, 1969; Sellers, 1969; North, 1975; to name but a few) are results of this recognition. In spite of all efforts, however, the causes of the ice ages cannot be said to be known. Many theories exist and also much disagreement about them. It is the belief of most investigators that variations in the incoming solar energy and in the concentration of dust in the upper atmosphere, which may be called external factors, constitute the dominant forcing. But, unfortunately, the response of the climate system to this forcing depends on a large number of internal feedback mechanisms. At present, we are able to describe at least some of these mechanisms qualitatively, but, with few exceptions, we fail to quantify them (Kellogg, 1975).

Most models in which interaction between ice sheets and atmospheric conditions is possible (mostly by ice-albedo-surface temperature feedback) are deterministic. They give the position of some ice line for given values of the solar constant and the atmosphere's transmissivity for long-wave radiation. A serious drawback of these EBM's is the assumption of instantaneously responding ice sheets. Use has been made of a sea-level isotherm as ice line (e.g. Budyko, 1969), or of a more smooth transition from no to total ice cover (Oerlemans and Van den Dool, 1978). Recently, a natural step has been made by Pollard (1978) who incorporated simple ice-sheet mechanics into an EBM.

Conditions during the last ice age are often used to tune or verify climate models and ice-age theories. However, in such procedures serious difficulties are involved, among which is the fact that we do not know anything about the variability 
of ice sheets due to random forcing. This point is relevant through the very nature of the physical system that establishes the earth's climate. One of its fundamental characteristics is the presence of turbulence (more or less at random occurring weather events, in this context) resulting from flow instabilities. A consequence is the impossibility of determining the equilibrium state (with regard to external forcing) of the ice sheets from an "instantaneous" observational picture as given by CLIMAP (1976). Due to the presence of random forcing some uncertainty has to be expected. Hasselmann (1976) presented a detailed discussion on this topic and constructed a formal framework for stochastic climate models based on theoretical concepts from the field of statistical mechanics. In this paper we will basically follow his approach.

The main goal of the present study is to gain insight in how a continental ice sheet reacts on random weather fluctuations. The approach will contain several crude approximations, but should be sufficiently accurate to investigate the importance of random forcing.

It is generally felt that the interaction between ice sheets and standing planetary waves constitutes an important feedback mechanism in the climate system. Without doubt, large ice sheets in the Northern Hemisphere will establish a zonally asymmetric forcing of the atmosphere, both thermal and orographic. The response of the atmosphere, in its turn, changes the conditions in the ice sheet's environment, thereby affecting their evolution. Therefore, it seems highly desirable to include this interaction in the model to be employed. An attempt in this direction will be made.

The present paper is closely related to those by Frankignoul and Hasselmann (1977) and, in particular, by Lemke (1977). In the latter, the response of the zonally averaged temperature (at sea level) to random forcing is studied by a stochastically driven EBM. The damping in this model, necessary to avoid infinite growth of the temperature variance, is determined by the nature of the radiation budget. Here, this damping will be derived from the crude mechanics of a continental ice sheet. Lemke's study and the present one may thus be regarded as complementary.

\section{Basic idea and strategy}

The intention is to carry out an analysis with simple mathematical tools, so we need to construct
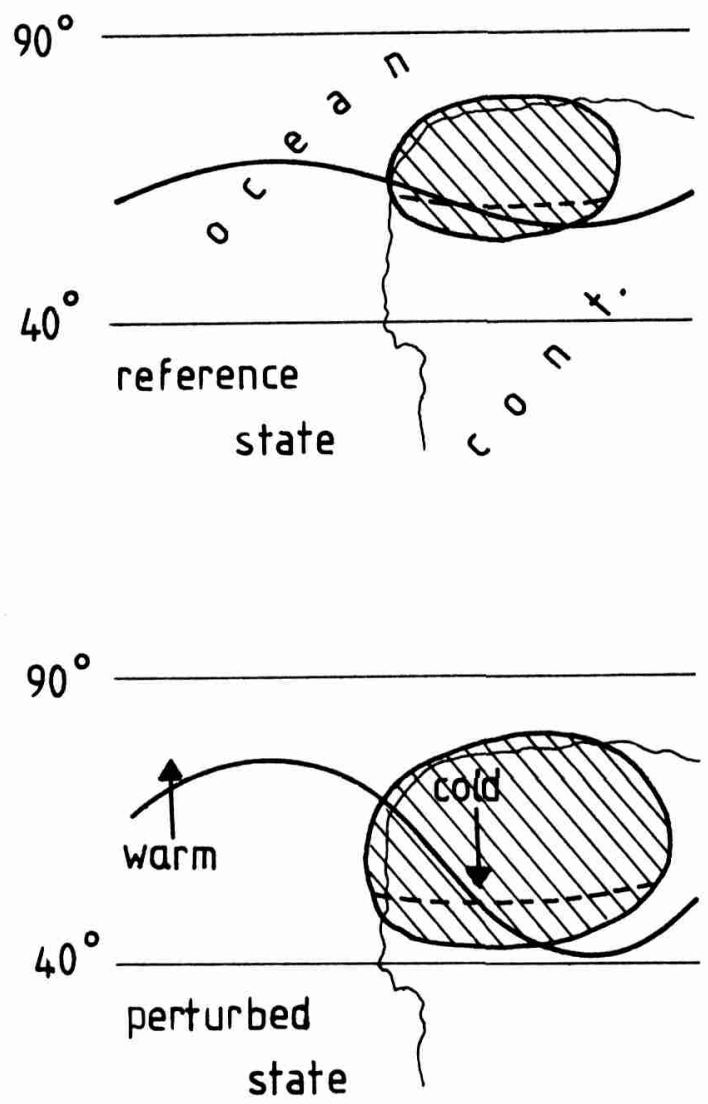

Fig. 1. Schematic illustration of continental ice-sheet variability and associated atmospheric conditions. The ice sheet is shaded. The dashed line represents the equilibrium line which separates the ablation and accumulation zones. The heavily drawn solid line indicates the standing wave in the $500 \mathrm{mb}$ geopotential height field.

a very schematic picture of a continental ice sheet and the ice sheet-atmosphere feedback loop.

We will consider Northern Hemisphere ice sheets only. In contrast to the Antarctic one, the Northern Hemisphere ice sheets are subject to atmospheric conditions that are highly asymmetric with respect to their centres. Going southward over the sheet we cross the equilibrium line which separates the accumulation zone from the ablation zone (indicated in Fig. 1 by the dashed line). The equilibrium line will play a central role in our discussion. Its position will serve as the agent for the interaction between ice sheet and atmosphere.

It is obvious that the presence of large ice sheets 
strongly forces standing planetary waves. Ample evidence exists that the phase of stationary planetary waves is such that the ridge of the geopotential height wave at $500 \mathrm{mb}$ lies downstream of the heat source and just upstream of the mountain range (linear theory: e.g. Smagorinsky, 1953; Döös, 1962, Derome and Wiin-Nielsen, 1971; Egger, 1976a, b; experiments with general circulation models: e.g. Kasahara and Washington, 1971; Manabe and Terpstra, 1974; Sommerville et al., 1974; observational evidence: e.g. Van Loon, 1973; Lau, 1979). Since ice sheets act as extensive mountain ranges and heat sinks, we may expect a picture as shown in Fig. 1. It reflects the main conclusion emerging from the studies mentioned above: if an ice sheet grows the standing wave pattern becomes more pronounced, with the trough over or just downstream of the sheet. Corresponding surface conditions are likely to establish a positive feedback by "more than normal" advection of cold air over the ice sheet (see arrows in Fig. 1).

Besides the forcing of large-scale waves and their associated impact on the boundary layer, a "direct" feedback also exists. The most dramatic effect is the increase of the yearly mean surface albedo if ice cover occurs; it causes the net incoming energy to decrease. Although this is partly compensated for by a decreased amount of outgoing radiation, the net effect is a reduced amount of energy available for ablation, or, equivalently, a southward shift of the equilibrium line. Again, the feedback seems to be positive.

Numerous effects obscuring the picture may be mentioned. Speculation on all kinds of physical processes has been extensive and it is not the intention to list them here. Pittock et al. (1978) provide a useful overview. Here it should be stated that the considerations given above are not crucial to the development of the model in the following sections. They serve as motivation for including ice sheet-atmosphere feedback. As a starting point we simply adopt that this feedback may be important and that the bulk of it may be expressed by a linear relationship between the position of the equilibrium line and the ice-sheet edge. In the case of positive feedback, the equilibrium line tends to follow the ice-sheet edge. If the feedback is negative, the equilibrium line and ice-sheet edge move in opposite directions.

Our strategy, illustrated in Fig. 2, will be as

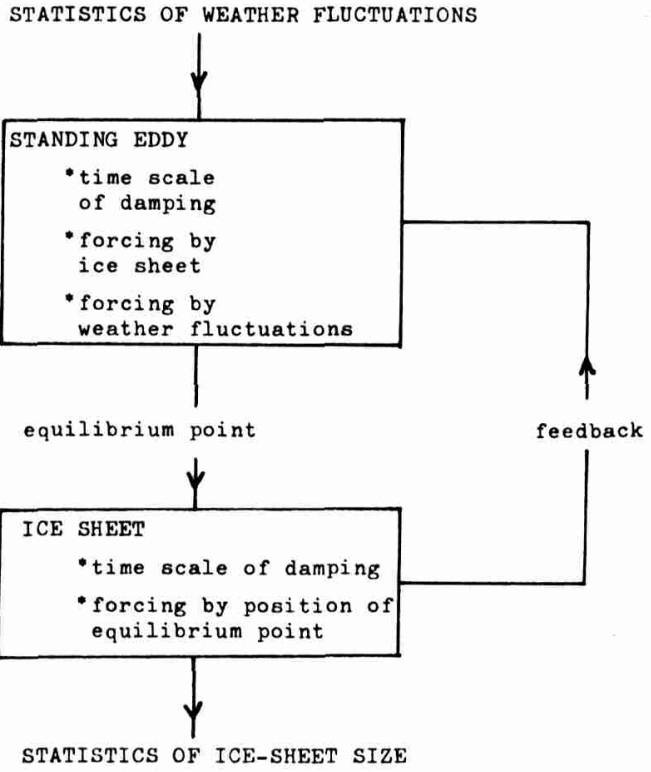

Fig. 2. Structure of the model. It has two basic climate components: the ice sheet and the standing wave in the atmosphere which are coupled through the position of the equilibrium point. The factors affecting each component are indicated. Statistics of weather fluctuations form the input of the model, whereas statistics of the ice-sheet size result.

follows. A two-dimensional (height and latitude) model of a continental ice sheet will be employed. It will be forced by varying the position of the equilibrium line (to be called equilibrium point from now on) and damped by its own crude mechanics. Linearization around a reference state (in the present case, the equilibrium state with respect to the external forcing) yields a linear first-order differential equation describing the evolution of the sheet. The equilibrium-point position with respect to the reference state, denoted by $\Delta^{\prime}$, is regarded as a measure of the standing wave forced by the ice sheet and random weather fluctuations. This may be formulated in a linear differential equation describing the evolution of $\Delta^{\prime}$. Combining these equations by elimination of $\Delta^{\prime}$ yields a stochastic second-order differential equation for the ice-sheet size. This type of equation is well known in statistical mechanics, so we can use existing theory. Time spectra of the ice-sheet size will result, from which other interesting quantities may be derived. 


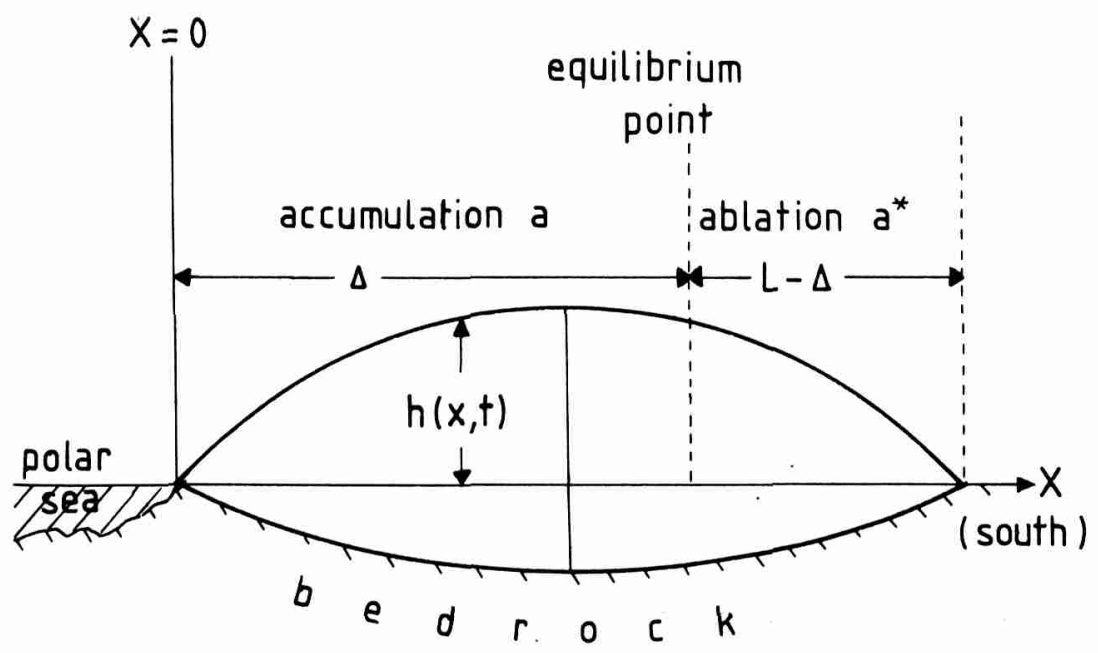

Fig. 3. Schematic picture of a continental ice sheet in the Northern Hemisphere. The total sheet width is $L$; it is divided into an accumulation zone and an ablation zone. The equilibrium point is at $x=\Delta$.

\section{The ice-sheet model}

In this section we will discuss a rephrased form of the ice-sheet model proposed by Nye (1959) and elaborated further by Weertman $(1961,1976)$.

Fig. 3 is a picture of the sheet. It is twodimensional (height and north-south direction) and supposed to flow as a perfect plastic substance according to

$h(x, t)=\sigma\left[\frac{1}{2} L(t)-\left|x-\frac{1}{2} L(t)\right|\right]^{\frac{1}{2}}$

In eq. (1), $h(x, t)$ is the height of the sheet, $L$ the width, and $\sigma$ a parameter specifying the height-towidth ratio which depends on the properties of ice. The surface beneath the sheet reacts in such a way that an isostatic balance is maintained. For a rock density of three times that of ice, the suppression of the surface amounts to $\frac{1}{2} h$. Atmospheric conditions affecting the evolution of the sheet are represented by two zones: the accumulation zone $(0 \leqslant x<\Delta)$ with constant accumulation rate $a$, and the ablation zone $(x \geqslant \Delta)$ with constant ablation rate $a^{*}$. These zones are separated by the equilibrium point at $x=$ $\Delta$. This representation of the forcing of the ice sheet is very rough, of course, but it is adequate for a first survey. It should be noted that use of the snow-line concept (Weertman, 1961) would not give very different results because a linear analysis around a reference state will be carried out.

The total accumulation in the region $x<\frac{1}{2} L$ equals the loss of ice into the Polar Sea, so there is no horizontal flow of ice through the centre of the sheet. For the southern half of the sheet, the conservation law for ice mass may be expressed as

$\frac{d}{d t} \int_{\frac{t}{2} L}^{L} \frac{3}{2} h(x, t) d x=a\left(\Delta-\frac{1}{2} L\right)-a^{*}(L-\Delta)$

After integration and rearrangement of terms we get

$\frac{d L}{d t}=-\gamma L^{\frac{1}{2}}+\beta \Delta L^{-\frac{1}{2}} \equiv E$

where

$\gamma=2 \sqrt{8}\left(a^{*}+\frac{1}{2} a\right) / 3 \sigma, \quad \beta=2 \sqrt{8}\left(a^{*}+a\right) / 3 \sigma$

Given the accumulation and ablation rates, the evolution of the sheet is fully described by eq. (3). If these rates are constant in time, an equilibrium state exists. It is given by

$L_{0}=\frac{\beta}{\gamma} \Delta_{0}$

In order to make the ice-sheet model more tractable, we linearize eq. (3) around a reference state. We regard this state as being the equilibrium state corresponding to the external forcing of the climate system (e.g. the distribution of incoming solar energy). The ice sheet will be internally forced by variations in the position of the equilibrium point, 
while $\beta$ and $\gamma$ are fixed; so we write

$\frac{d L^{\prime}}{d t}=\left.\frac{\partial E}{\partial L}\right|_{L_{0}} \cdot L^{\prime}+\left.\frac{\partial E}{\partial \Delta}\right|_{\Delta_{0}} \cdot \Delta^{\prime}$

From eq. (3) we obtain

$\left.\frac{\partial E}{\partial L}\right|_{L_{0}}=-\gamma L_{0}^{-\frac{1}{2}},\left.\quad \frac{\partial E}{\partial \Delta}\right|_{\Delta_{0}}=\beta L_{0}^{-\frac{1}{2}}$

where used has been made of the equilibrium condition (4). Since $\partial E /\left.\partial L\right|_{L_{0}}<0$, the equilibrium state is stable with regard to perturbations in $L$. The relaxation time of the ice sheet is given by $\gamma^{-1} L_{0}^{\ddagger}$. For current values of the constants involved, this scale is of the order of 5000 years for a large sheet.

\section{Forcing of the atmosphere}

As discussed in Section 2, continental ice sheets create their own climate to some extent by forcing planetary waves and modifying the boundary layer. At this point we need to express this link in the climate system in terms of the variables occurring in our simple ice-sheet model.

The easiest way to do this is by identifying $\Delta^{\prime}$ with the amplitude of a standing eddy in the yearly mean surface temperature. This is justified by the fact that in a broad sense, the equlibrium line follows some isotherm (e.g. Sugden and John, 1976). Accepting this concept, the relation between $L^{\prime}$ and $\Delta^{\prime}$ describes the ice sheet-atmosphere interaction. We write

$$
\frac{d \Delta^{\prime}}{d t}=-\mu \Delta^{\prime}+\alpha L^{\prime}+\varepsilon(t)
$$

Eq. (7) formulates to first order the behaviour of the equilibrium point with respect to that of the reference ice sheet. The first term on the right-hand side represents a damping force; the constant $\mu$ is determined by the characteristic time scale of standing planetary waves. This should also include effects like the response of the oceanic surface circulation and the biosphere. Since we do not explicitly account for the yearly cycle, a value of at least 1 year should be used to be consistent with the model. The second term describes the forcing of the standing eddy by the ice sheet, again with respect to the reference state $\left(L^{\prime}=0\right)$. Formulated in this way, the interaction is determined by the constant a. Finally, the last term in eq. (7) represents the stochastic forcing, which is the energy source of the model.

If $\varepsilon(t) \equiv 0$, eq. (7) has the stable asymptotic solution

$\frac{\Delta^{\prime}}{L^{\prime}}=\frac{\alpha}{\mu} \equiv \alpha^{*}$

Given $\mu$, the non-dimensional constant $\alpha^{*}$ prescribes to what extent the position of the equilibrium point tends to follow the ice-sheet edge.

\section{The complete model}

To arrive at one equation describing the complete model, we rewrite eq. (5) as $d L^{\prime} / d t=-\lambda L^{\prime}+$ $c \Delta^{\prime}$ ( $\lambda$ and $c$ are given in eq. (6)), and combine it with eq. (7), thus yielding the second-order differential equation

$\frac{d^{2} L^{\prime}}{d t^{2}}+(\lambda+\mu) \frac{d L^{\prime}}{d t}+c \mu\left(\frac{\lambda}{c}-\alpha^{*}\right) L^{\prime}=c \varepsilon(t)$

This type of equation is well known; it describes how a random input signal is transformed by an electrical band-pass filter, or how a pendulum hanging in a turbulent fluid behaves.

In the homogeneous case, i.e. $\varepsilon(t) \equiv 0$, eq. (9) describes the free movement of a damped harmonic oscillator. The solution may be found in any textbook on classical mechanics; it is given by

$L^{\prime}(t)=C_{1} e^{p_{1} t}+C_{2} e^{p_{2} t}$

where $C_{1}$ and $C_{2}$ are constants and $p_{1}$ and $p_{2}$ are the solutions of the characteristic equation

$p^{2}+(\lambda+\mu) p+c \mu\left(\frac{\lambda}{c}-a^{*}\right)=0$

It is easy to show that the ice sheet will expand indefinitely $\left(L^{\prime} \rightarrow \infty\right)$ if $\alpha^{*}>\lambda / c$. For realistic values of the accumulation and ablation rates $\left(a^{*}=\right.$ $1 \mathrm{~m} /$ year, $a / a^{*}=0.3$; e.g. Birchfield, 1977), we find $\lambda / c=0.88$, so the ice sheet becomes unstable if $\alpha^{*}$ $>0.88$. Therefore, in order to guarantee stability, the equilibrium point cannot follow the ice-sheet edge but should stay a bit behind. No matter how low the accumulation rate is, for $a^{*}>1$ instability always occurs. This is physically quite clear: if the accumulation zone grows faster than the ice 
sheet, the total ablation ultimately becomes zero. Apparently, our model climate system is sensitive.

We will now consider the case with forcing by random "weather" fluctuations representing a stationary stochastic process. If $\overline{\varepsilon(t)}=0$, where the bar denotes an average over a sufficiently long time interval, the linearity of the model assures that $\overline{L^{\prime}(t)}$ $=0$. The spectral density function of $L^{\prime}(t)$, denoted by $Y(\omega)$, may be found by a Fourier transform of eq. (11) (Batchelor, 1956; for a more general discussion: Soong, 1973). It reads

$$
Y(\omega)=\frac{c^{2} \phi(\omega)}{\left[c \mu\left(\frac{\lambda}{c}-\alpha^{*}\right)-\omega^{2}\right]^{2}+(\lambda+\mu)^{2} \omega^{2}}
$$

where $\phi(\omega)$ is the spectral density function of $\varepsilon(t)$.

At this point it is useful to have a look at the orders of magnitude of the various parameters. Current values of the constants involved give $c \simeq 0.0003$ for a large sheet. The feedback between ice sheet and standing eddy is fully determined by $\alpha^{*}$ and $\mu$; they may be said to form the "feedback parameter plane". For a part of this plane, roughly given by $\mu>0.1$ and $\alpha^{*}<0.7$, it may be shown that the shape of the spectrum given by eq. (12) approaches that of a first-order stochastic climate model with linear damping (Hasselmann, 1976), the corresponding damping coefficient being $c\left(\lambda / c-\alpha^{*}\right)$. This result is not surprising because in this case the behaviour of the equilibrium-point position appears as white noise to the ice sheet. If the feedback is strong (large $\alpha^{*}$ ) and appears on a relatively large time scale (small $\mu$ ), however, the second-order model gives different results.

\section{Variability of the ice-sheet size}

To arrive at a picture of the spectrum $Y(\omega)$, we assume that $\varepsilon(t)$ may be regarded as a white-noise process. Inter-annual variability seems to be most suitable to derive the strength of the white noise, because the ice-sheet model "feels" the yearly mean mass balance only.

Formally, we define a new random process by

$\varepsilon^{*}(t)=\frac{1}{T} \int_{t-\frac{1}{2} T}^{t+\frac{1}{2} T} \varepsilon(\tau) d \tau$

The constant spectral level $\phi(0)$ of $\varepsilon(t)$ is then related to the variance of $\varepsilon^{*}(t)$ by

$$
\phi(0)=\overline{T \varepsilon^{*}(t)^{2}} / \pi
$$

Since we will employ inter-annual variability, we take $T=1$ year.

We use data from Oort (1977), and Oort and Rasmusson (1971). The relevant quantities are listed in Table 1. The second column gives the inter-annual standard deviation of the variance of yearly mean temperature $(T)$ due to standing eddies. From these data an estimate of $\overline{\varepsilon^{* 2}}$ may be derived immediately by assuming that $\partial T / \partial x$ is constant. We accept $5 \cdot 10^{4} \mathrm{~km}^{2} \mathrm{yr}^{-2}$ to be a typical value.

Fig. 4 shows spectra for three sets of values for $\mu$ and $\alpha^{*}$. The size of the ice sheet in the reference state is $L_{0}=2000 \mathrm{~km}$. Increasing the time scale of the equilibrium-point position (smaller $\mu$ ) shifts the curve to the right, thereby increasing the total variance.

The most interesting quantity is the total variance of the ice-sheet size. It may be obtained by integration of the spectral density function over frequency, yielding (e.g. Carmichael and Smith, 1962)

$$
\overline{L^{\prime 2}}=\int_{-\infty}^{\infty} Y(\omega) d \omega=\frac{\pi c \phi(0)}{\mu(\lambda+\mu)\left(\frac{\lambda}{c}-\alpha^{*}\right)}
$$

It is easily seen that, for ice sheets larger than, say, $100 \mathrm{~km},(\lambda+\mu)$ may be replaced by $\mu$. Therefore, the variance is proportional to $\mu^{-2}$, i.e. to the square of the relaxation time of the equilibrium point position. Also, a stronger interaction between ice sheet and atmosphere (larger $a^{*}$ ) increases the variability. Fig. 5 shows the standard deviation of

Table 1. Quantities used in estimating the level of white-noise forcing $\overline{\varepsilon^{2}}$. Data are from Oort (1977) and Oort and Rasmusson (1971)

\begin{tabular}{llll}
\hline $\begin{array}{l}\text { Latitude } \\
\left({ }^{\circ} \mathrm{N}\right)\end{array}$ & $\begin{array}{l}\sigma \text { of }\left[\bar{T}^{\prime 2}\right] \\
\text { at } 1000 \mathrm{mb} \\
\left(\mathrm{K}^{2}\right)\end{array}$ & $\begin{array}{l}\partial \bar{T} / \partial x \text { at } \\
1000 \mathrm{mb} \\
(\mathrm{K} / 100 \mathrm{~km})\end{array}$ & $\begin{array}{l}\text { Estimated } \overline{\varepsilon^{2}} \\
\left(10^{4} \mathrm{~km}^{2} \mathrm{yr}^{-2}\right)\end{array}$ \\
\hline 45 & 0.9 & 0.64 & 2.2 \\
50 & 1.7 & 0.53 & 6.1 \\
55 & 2.2 & 0.55 & 7.3 \\
60 & 2.4 & 0.64 & 5.9 \\
65 & 2.8 & 0.78 & 4.6 \\
70 & 3.2 & 0.69 & 6.7 \\
75 & 3.6 & 0.67 & 8.0 \\
\hline
\end{tabular}




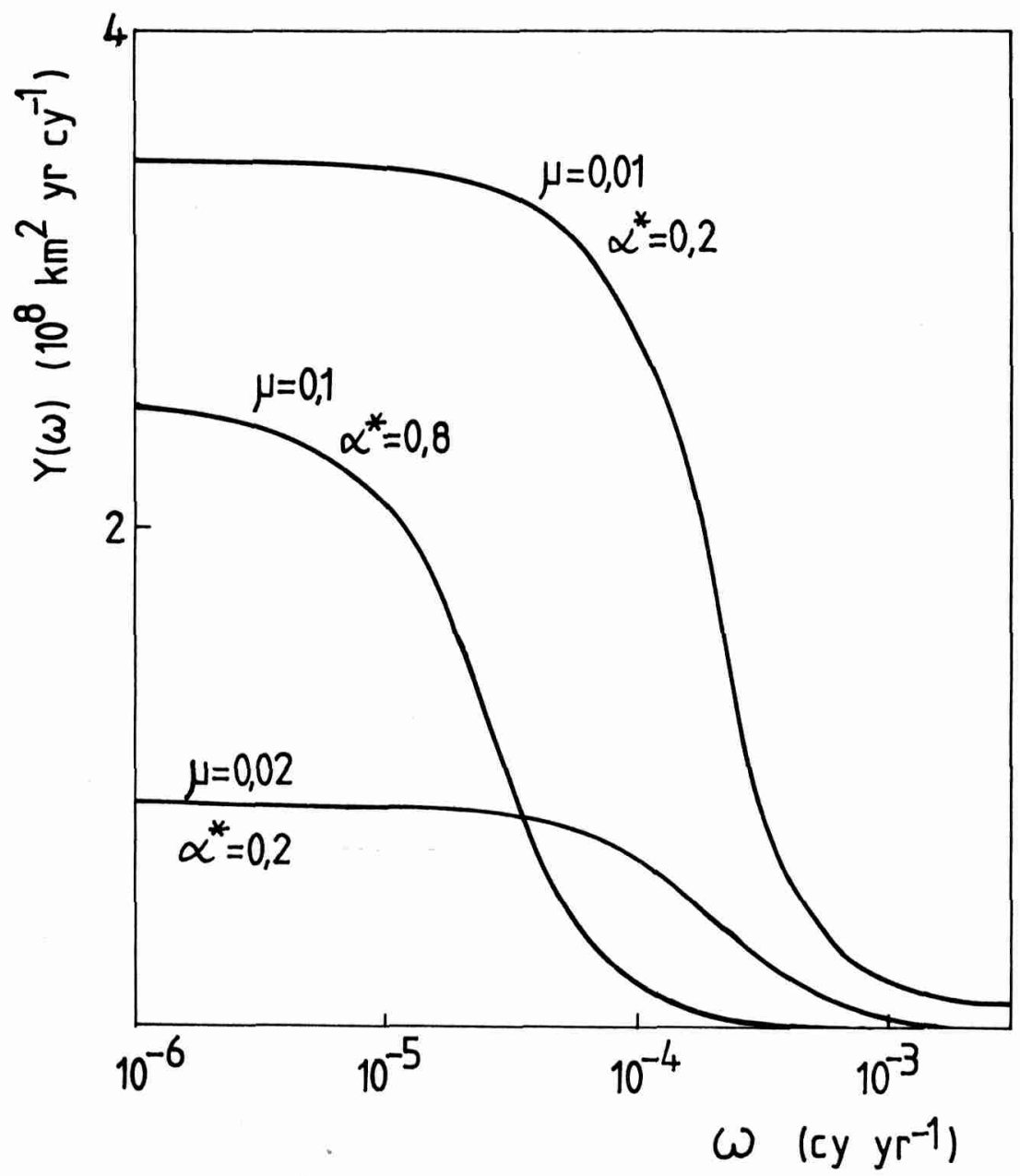

Fig. 4. Ice-sheet spectra for various values of the feedback parameters $\alpha^{*}$ and $\mu$. The ice-sheet size in the reference state is $2000 \mathrm{~km}$.

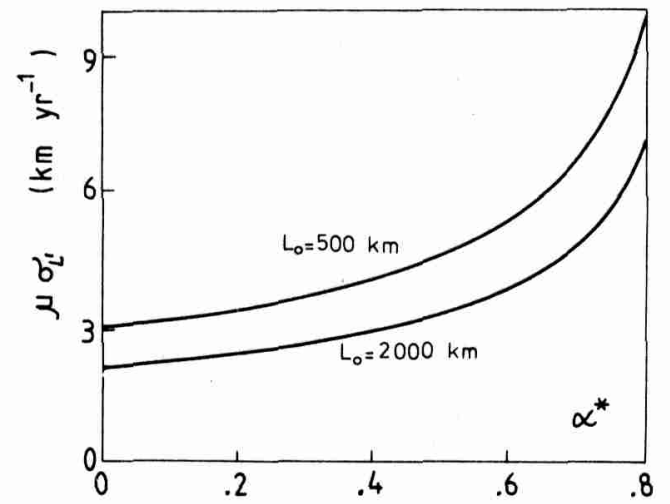

Fig. 5. Standard deviation of the ice-sheet size for a small and a large ice sheet, as a function of the feedback parameter $\alpha^{*}$. the ice-sheet size, multiplied by $\mu$, for a small and a large ice sheet, as a function of $\boldsymbol{\alpha}^{*}$. Apparently, a small ice sheet shows more variability than a large one. We should keep in mind, however, that a larger ice sheet will have a more profound influence on the atmospheric circulation, which increases the appropriate value of $\alpha^{*}$.

\section{Discussion}

We now return to the question posed in the Introduction-What is the order of magnitude of ice-sheet size variability due to random forcing? Unfortunately, the foregoing analysis showed that the standard deviation of the ice-sheet size, $\sigma_{L^{\prime}}$, is 
very sensitive to most model parameters. We have

$$
\begin{aligned}
\sigma_{L^{\prime}} & \sim L_{0}^{-\dagger} \\
& \sim \mu^{-1} \\
& \sim\left(\frac{\lambda}{c}-\alpha^{*}\right)^{-1}
\end{aligned}
$$

Since we do not know with some accuracy the appropriate values of $\mu$ and $\alpha^{*}$, it would be highly unrealistic to give a specific value of $\sigma_{L^{\prime}}$. Instead, a range of values should be indicated, thus showing whether random forcing of sizable ice sheets is potentially important or not.

As discussed earlier, $\mu^{-1}$ is the damping time scale of the equilibrium-point position. This scale should include all effects (sea ice, oceanic circulation, biosphere adjustment, etc.) except the inertia of the ice sheets. Probably, the effective value of $\mu$ is mainly determined by the response times of the oceanic circulation and the sea-ice distribution. We accept 0.2 and $0.01 \mathrm{yr}^{-1}$ to be the limits for $\mu$. The strength of the feedback between ice-sheet size and equilibrium-point position, given by $a^{*}$, is also not known. The existence of positive feedback due to the albedo effect is without doubt, but the role of planetary waves is uncertain. Again, we have to accept a wide range of values. As limits for $a^{*}$ we take 0.2 and 0.7 .

From Fig. 5 we find that the limits in the feedback parameter plane given above lead to a standard deviation of the ice-sheet size between 10 and $500 \mathrm{~km}$ for a large ice sheet. This result does not make us much wiser- $10 \mathrm{~km}$ is negligible, whereas $500 \mathrm{~km}$ is a lot. We may state that random forcing has the potential to be important, but not without a strong positive feedback between ice sheet and atmospheric conditions surrounding it.

The scenario for a climate system presented in this paper is kept fairly general, in the hope that future deterministic modelling may provide more accurate estimates of the parameters $\mu$ and $\alpha^{*}$. In that case, a new estimate of ice-sheet size variability may be derived immediately from eq. (16).

\section{Acknowledgement}

I thank my colleagues and the referees for their useful comments.

\section{REFERENCES}

Batchelor, G. K. 1956. The theory of homogenous turbulence. Cambridge University Press.

Birchfield, G. E. 1977. A study of the stability of a model continental ice sheet subject to periodic variations in heat input. J. Geophys. Res. 82, 4909-4913.

Budyko, M. I. 1969. The effect of solar radiation variations on the climate of the earth. Tellus 21, 611-619.

Carmichael, R. D. and Smith, E. R. 1962. Mathematical tables and formulas. New York: Dover Publications.

CLIMAP, 1976. The surface of the ice-age earth. Science 191, 1131-1137.

Derome, J. and Wiin-Nielsen, A. 1971. Response of a middle latitude model to forcing by topography and stationary heat sources. Mon. Wea. Rev. 99, 564-576.

Döös, B. R. 1962. The influence of exchange of sensible heat with the earth's surface on the planetary flow. Tellus 14, 133-147.

Egger, J. 1976a. On the theory of the steady perturbations in the troposphere. Tellus 28, 381-390.

Egger, J. 1976b. The linear response of a hemispheric two-level primitive equation model to forcing by topography. Mon. Wea. Rev. 104, 351-364.

Frankignoul, C. and Hasselmann, K. 1977. Stochastic climate models, Part 2, Application to sea-surface temperature anomalies and thermocline variability. Tellus 29, 289-305.

Hasselmann, K. 1976. Stochastic climate models, Part 1, Theory. Tellus 28, 473-485.

Kasahara, A. and Washington, W. 1971. General circulation experiments with a six-layer NCAR model, including orography, cloudiness and surface temperature calculations. J. Atmos. Sci. 28, 657-701.

Kellogg, W. W. 1975. Climate feedback mechanisms involving the polar regions. In: Climate of the arctic. Geophysical Institute, University of Alaska.

Lau, N.-C. 1979. The observed structure of tropospheric stationary waves and the local balances of vorticity and heat. To appear in J. Atmos. Sci.

Lemke, P. 1977. Stochastic climate models, Part 3, Application to zonally averaged energy models. Tellus 29, 385-392.

Manabe, S. and Terpstra, T. B. 1974. The effect of mountains on the general circulation of the atmosphere as identified by numerical experiments. $J$. Atmos. Sci. 31, 3-42.

North, G. R. 1975. Theory of energy-balance climate models. J. Atmos. Sci. 32, 1301-1307.

Nye, J. F. 1959. The motion of ice-sheets and glaciers. $J$. Glaciol. 3, 493-507. 
Oerlemans, J. and van den Dool, H. M. 1978. Energy balance climate models: stability experiments with a refined albedo and updated coefficients for infrared emission. J. Atmos. Sci. 35, 371-381.

Oort, A. H. 1977. The interannual variability of atmospheric circulation statistics. NOAA Prof. Paper No. 8.

Oort, A. H. and Rasmusson, E. M. 1971. Atmospheric circulation statistics. NOAA Prof. Paper No. 5.

Pittock, A. B., Frakes, L. A., Jenssen, D., Peterson J. A. and Zillman, J. W. 1978 Climatic change and variability, a southern perspective. Cambridge University Press.

Pollard, D. 1978. An investigation of the astronomical theory of the ice ages using a simple climate-ice sheet model. Nature 272, 233-235.

Sellers, W. D. 1969. A global climatic model based on the energy balance of the earth-atmosphere system. $J$. Apl. Meteor. 8, 392-400.

Smagorinsky, J. 1953. The dynamical influence of large- scale heat sources and sinks on the quasi-stationary motions of the atmosphere. Quart. J. Roy. Met. Soc. 79, 342-366.

Sommerville, R. C. J., Stone, P. H., Halem, M., Hansen, J. E., Hogan, J. S., Druyan, L. M., Russell, G., Lacis, A. A., Quirk, W. J. and Tenenbaum, J. 1974. The GISS model of the global atmosphere. J. Atmos. Sci. 31, 84-117.

Soong, T. T. 1973. Random differential equations in science and engineering. Academic Press.

Sugden, D. E. and John, B. S. 1976. Glaciers and landscape. Edward Arnold Ltd.

Van Loon, H., Jenne, R. L. and Labitzke, K. 1973. Zonal harmonic standing waves. J. Geophys. Res. 78, 4463-4471.

Weertman, J. 1961. Stability of ice-age ice sheets. $J$. Geophys. Res. 66, 3783-3792.

Weertman, J. 1976. Milankovitch solar radiation variations and ice age ice sheet sizes. Nature 261, 17-20.

\section{ОЦЕНКА НЕОПРЕДЕЛЕННОСТИ В РАЗМЕРАХ ЛЕДОВЫХ ЩИТОВ СЕВЕРНОГО ПОЛУШАРИЯ ИЗ-ЗА ОБРАТНОЙ СВЯЗИ С ПЛАНЕТАРНЫМИ ВОЛНАМИ}

Поведение континентальных ледовых шитов является ключевой проблемой в динамической климатологии. Кроме знания о равновесном состоянии этих щитов для заданных внешних условий (таких, как распределение падающей солнечной радиации и содержание $\mathrm{CO}_{2}$ в атмосфере), желательно что-нибудь знать об их изменчивости. Эта изменчивость-результат внутренних воздействий стохастического характера. Часть этих воздействий, помимо других механизмов, возбуждается самим щитом путем индуцирования планетарных волн в атмосфере.

В этой заметке дается оценка изменчивости границы льда, в которой в грубой форме принята обратная связь между размерами щита и планетарными волнами. Используется простая стохастическая модель вместе с описанием континентального ледового щита по Виртману. Основной результат анализа состоит в том, что стандартное отклонение положения краев достаточно большого щита в Северном полушарии находится в пределах 10-500 км. 